\title{
Scale Effect, International Outsourcing, and Welfare
}

\author{
Lo Chu-Ping* \\ Department of Agricultural Economics, National Taiwan University, Taipei, Taiwan \\ *Corresponding author: cplo@ntu.edu.tw
}

\begin{abstract}
We have presented a simple model to show that trade elasticity is determined by not only consumers' preferences, but also producers' comparative advantages in a world where trade is driven by both consumers' love-of-variety and producers' comparative advantages. In this model, scale matters in trade elasticity, with smaller countries tending to exhibit a larger one. In addition to tradable intermediate goods, this model also shows that scale is a key factor influencing gains from trade. As a result, smaller countries that are engaged in more international outsourcing activities typically benefit with relatively greater gains from trade after trade liberalization.
\end{abstract}

Keywords: gains from trade, trade elasticity, international outsourcing, welfare

JEL Classification: F12; F16; O30.

Cite This Article: Lo Chu-Ping, "Scale Effect, International Outsourcing, and Welfare." Journal of Finance and Economics, vol. 6, no. 1 (2018): 26-31. doi: 10.12691/jfe-6-1-4.

\section{Introduction}

Trade elasticities, defined by the aggregate response of trade to shocks in trade costs, illustrate the resilience of exporters in the face of a sudden change in trade barriers. In the literature, a change in welfare (away from autarky) depends on only two sufficient statistics: the share of expenditure on domestic goods and trade elasticity [1]. ${ }^{1}$ Thus, an estimation of trade elasticities is important because it can be used to gauge a country's welfare performance in the face of an adjustment in trade policy.

In the model of monopolistic competition with a representative firm, trade elasticity is determined by consumers' preferences $[2,3,4]$. In this type of model where all differentiated producers export (no selection effects), trade elasticity equals the elasticity of substitution $(\sigma)$ minus one, denoted as $\sigma-1$. However, in the recent decades, a new strand in the literature specifies heterogeneous firms in terms of productivity. In particular, the Pareto distribution has become a good approximation for the distribution of firms' productivities $[5,6]$, as is the Fréchet distribution $[7,8]$. These distributions are characterized by a share parameter, $\theta$, which measures the degree of firm heterogeneity. When firms are heterogeneous such that only relatively high productive firms export (selection effects), Eaton and Kortum [8] and Chaney [9] show that trade elasticity is replaced by the share parameter $\theta$ when the selection effect arises. The result is striking, because the impact of the consumers' preferences on trade elasticities disappears, and the impact is completely replaced by a parameter on the supply side of the economy.

\footnotetext{
${ }^{1}$ Arkolakis, Arnaud, and Rodiguez-Clare [1] express the change in gains from trade by $\pi^{-1 / \varepsilon}$, where $\pi$ denotes the share of expenditure on domestic goods and $\varepsilon$ denotes trade elasticity.
}

The above models only address the trade of final goods. As an exception, Alvarez and Lucas [10] present a variation of the Eaton-Kortum model [8] in which each country produces one final good and a continuum of intermediate goods. Each country symmetrically aggregates the tradable intermediate goods via a Spence-Dixit-Stiglitz aggregate and then uses the aggregate intermediate goods to produce one variety of a final good exclusively for its own consumption. In their model, only intermediate goods are tradable while final goods are not.

In real practice, in contrast to the above literature, world trade is mixed with not only final goods but also intermediate goods. In order to maximize profits, final goods producers search for the lowest cost of intermediate goods suppliers by sourcing globally in order to minimize their general production cost $[11,12]$. Considering the fact that the number of intermediate-goods suppliers usually outnumbers that of differentiated final-goods providers substantially, it is feasible to argue that the trade of differentiated final-goods are more likely driven by love-of-variety, such that the selection effects are relatively small. In comparison, the trade of intermediate-goods is mainly driven by cost advantages, such that the selection effects are relatively large. To sharpen the contrast, this paper simply presumes that the final goods are of the Armington-type of final-goods (no selection effects), and that the tradable intermediate-goods are of the Eaton and Kortum [8] type of goods (with selection effects).

Global sourcing is also called vertical specialization, offshore production, or international outsourcing $[11,12,13,14]{ }^{2}$ Hereafter, we use the term international outsourcing for consistency in this paper. The above researches show that international outsourcing activities

\footnotetext{
${ }^{2}$ Using input-output tables from ten OECD and four emerging market countries, they estimate that international outsourcing accounts for $21 \%$ of these countries' exports and increased almost 30\% between 1970 and 1990.
} 
are carried out substantially and that the extent to these activities differs across countries.

As international outsourcing has prevailed in recent decades, final goods are being produced in different stages of production in different regions, such that intermediate goods are shipped across borders more than once [15]. Since the general price of the final goods already includes the values of all sources of intermediate goods, a country's trade volume (in gross value) might be exaggerated over its true value-added due to double counting on the tradable intermediate goods. These intermediate goods, that are first shipped abroad as raw materials and then shipped back as ingredients to the final goods, not only bring up the gross trade volume but also "double count" the trade costs for these intermediate goods across national borders more than once. Often, a country imports intermediate goods to produce final goods for exports; meanwhile, the country also exports intermediate goods that are used as inputs by other countries to produce final goods for their exports. As a result, a country's trade volume is more sensitive to trade costs if the country is engaged in more intermediate-goods trade, since intermediate goods are more exposed to transportation frictions while they are usually shipped back and forth more than once. In this paper, we hence argue that a country's trade elasticity is affected by some country characteristics, such as its size and the extent to which it is engaged in international outsourcing. Reasonably, smaller countries that are engaged in more intermediate-goods trade should be more sensitive to the trade costs, since relatively more of their trade is exposed to trade barriers. Therefore, we argue that smaller countries, which are engaged in more intermediate-goods trade, should benefit relatively more from trade liberalization than the other countries.

The rest of the paper runs as follows. Section 3 presents a model to address how international outsourcing reshapes trade elasticity. Section 4 calculates country-specific trade elasticity and gains from trade. Section 5 concludes.

\section{The Model}

To capture how trade costs disproportionately increase when trade is mixed with intermediate and final goods, we revisit Eaton and Kortum's [8] model by adding the Armington-type of final goods. In this way, we address how consumers' love of variety and firms' comparative advantage might be matched in strength when determining trade volume.

Consider a world of $N$ countries, mixed with Armington-type [2] final goods and Eaton-Kortum-type [7] intermediate goods. Country $i$ produces one variety of differentiated final good $y_{i}$ and an array of intermediate goods $x_{i}$, for which the common input is labor. Individuals have identical constant elasticity of substitution (CES) preferences on the final goods, and the elasticity of substitution is $\sigma$. A representative household in country $n$ maximizes her utility:

$$
U_{n}=\left[\sum_{i=1}^{N} y_{i n}^{(\sigma-1) / \sigma}\right]^{\sigma /(\sigma-1)},
$$

where $y_{i n}$ is country $n$ 's consumption of the goods from country $i$. Trade incurs an iceberg transportation cost as $\tau_{\text {in }} \geq 1$ and $\tau_{i i}=1, \forall i, n$.

\subsection{Production Function}

It is widely known that a country's domestic business services are generally embedded in its manufacturing exports [15]. Hence, in this paper, the production of any variety of a final good takes the Cobb-Douglas form and requires a combination of headquarter services and a bundle of intermediate goods:

$$
y_{i}=A_{i} l_{i}^{1-\alpha} x_{i}^{\alpha}
$$

where $A_{i}$ is productivity shifter, $l_{i}$ denotes headquarter services that are not tradable, and $\alpha$ is the share of tradable intermediate goods in output of the final good production. The tradable intermediate goods are not for direct consumption, but instead are used as inputs in the production of final goods. In a way similar to Eaton and Kortum [7], the bundle of intermediate goods is aggregated by a Cobb-Douglas function across the continuum varieties of intermediate goods:

$$
x_{i}=\exp \int_{0}^{1} \ln x_{i}(\omega) d \omega,
$$

which Caliendo and Parro [16] refer to as the composite intermediate good aggregate.

\subsection{The Intermediate Goods}

The intermediate goods are Eaton-Kortum-type continuum goods $\omega \in[0,1]$. An intermediate good producer in country $i$ draws its productivity $z_{i}(\omega)$ from a Fréchet distribution $\operatorname{Pr}(Z \leq z)=F_{i}(z)=e^{-T_{i} z^{-\theta}}$, where $T_{i}$ denotes the technology of country $i$ that represents the absolute advantage of the country. Firms in a country, that is endowed with a higher level of technology, tend to have a greater possibility of drawing a more efficient productivity. The parameter $\theta$ reflects the dispersion of productivities in the continuum of goods so that it governs comparative advantages within this continuum.

In (3), the price distribution of the intermediate-goods is then given by $G_{n}(p)=1-\prod_{i=1}^{N}\left(1-G_{i n}(p)=1-e^{-\tilde{\Phi}_{n} p}\right.$ in country $n$, where $\quad \tilde{\Phi}_{n} \equiv \sum_{i=1}^{N} T_{i}\left(w_{i} \tau_{i n}\right)^{-\theta} \quad$ and $G_{i n}(p)=1-F_{i}\left(w_{i} \tau_{i n} / p\right)$ [8]. Here, $w_{i}$ denotes the unit labor cost, the wage in country $i$. With the Cobb-Douglas preferences, the aggregate price of the intermediate good bundle is given by $\tilde{P}_{n}=e^{-\eta_{e} / \theta} \tilde{\Phi}_{n}^{-1 / \theta}$ in country $n$, where $\eta_{e} \equiv-\int_{0}^{\infty} \ln (x) e^{-x} d x$ is the Euler's constant.

Implied in (2), the unit cost of producing the final good in country $i$ is $\tilde{A}_{i}^{-1}\left(w_{i}^{1-\alpha} \tilde{P}_{i}^{\alpha}\right)$ and the unit price 
is then given by $p_{i}=\frac{\sigma \tilde{A}_{i}^{-1}\left(w_{i}^{1-\alpha} \tilde{P}_{i}^{\alpha}\right)}{\sigma-1}$, where $\tilde{A}_{i}^{-1} \equiv A_{i}^{-1} \alpha^{-\alpha}(1-\alpha)^{-(1-\alpha)}$. Here, the labor requirement for producing the headquarter service is a fixed sunk cost $l_{i}^{0}$, so that the total cost of producing the final-good is $c_{i}=l_{i}^{0}+\tilde{A}_{i}^{-1}\left(w_{i}^{1-\alpha} \tilde{P}_{i}^{\alpha}\right) y_{i}$.

The total output of the final good in country $i$ is $Y_{i}=p_{i} y_{i}$. Supposed the number of countries in the Armington world is substantially large, such that the elasticity of demand for each differentiated final good equals the elasticity of substitution as shown in (1). Then, the total output of the final good in country $i$ can be rewritten as $Y_{i}=\left[\frac{\sigma \tilde{A}^{-1}\left(w_{i}^{1-\alpha} \tilde{P}_{i}^{\alpha}\right)}{\sigma-1}\right]^{\sigma} \Pi_{i}^{1-\sigma}$, where $\Pi_{i}^{1-\sigma}=\sum_{n=1}^{N} \tau_{i n}^{1-\sigma} P_{n}^{\sigma-1} X_{n}$. Here, $X_{n}=w_{n} L_{n}$ denotes the total income of country $n$.

In monopolistic competition, the total labor force devoted to final good production is the sum of the fixed sunk cost and the headquarter services as $\tilde{\sigma}^{-1} Y_{i} / w_{i}$, where $\tilde{\sigma}=\frac{\sigma}{1+(1-\alpha)(\sigma-1)} \cdot{ }^{3}$ The remaining labor of the country is then devoted to producing the intermediate goods $\tilde{Y}_{i}$, which represents the total output of the intermediate goods produced by country $i$. Hence, the labor market equilibrium in the intermediate good sector requires

$$
\tilde{L}_{i}=L_{i}-\tilde{\sigma}^{-1}\left(Y_{i} / w_{i}\right),
$$

where $\tilde{L}_{i}$ represents country $i$ 's total employment engaged in intermediate-goods production. 4 As the production of the intermediate goods is under perfect competition, we have $\tilde{Y}_{i}=w_{i} \tilde{L}_{i}$. Country $i$ 's total output of the intermediate goods can now be rewritten as

$$
\tilde{Y}_{i}=X_{i}-Y_{i} / \tilde{\sigma}
$$

where $X_{i}=w_{i} L_{i}$ represents the total income of country $i$.

Following Eaton and Kortum's [7] model, we use $T_{i}(t)=\phi_{i} \int_{0}^{t} r_{i} L_{i}(s) d s \quad$ to denote the accumulated technology of country $i$ that represents the absolute advantage of that country, in which $\phi_{i}$ denotes the research productivity of researchers and $r_{i}$ is country $i$ 's research intensity. Researchers produce patents specific to

3 The share of the fixed sunk cost is $Y_{i} / \sigma$. As implied in (2), the share of the headquarter services is as $(1-\alpha)\left(\frac{\sigma-1}{\sigma}\right) Y_{i}$. In sum, we obtain $\tilde{\sigma}=\frac{\sigma}{1+(1-\alpha)(\sigma-1)}$.

${ }^{4}$ In the Armington world, each country specifies one differentiated finalgood. the intermediate goods and acquire a fixed share of output as profits as $1 /(1+\theta)$ in their general equilibrium. ${ }^{5}$ Borrowing from their results, we then have

$$
\frac{\tilde{Y}_{i}}{1+\theta}=r_{i} w_{i} L_{i} \text {. }
$$

Combining (4) and (5), we obtain an output-to-income ratio as

$$
Y_{i} / X_{i}=\tilde{\sigma}\left[1-(1+\theta) r_{i}\right]
$$

Equation (6) implies that a high research intensity country tends to be engaged in more intermediate-goods production and less final-goods production. The probability that country $i$ is the cheapest source of a particular intermediate-goods exporter to country $n$ is $\tilde{\pi}_{i n}=\frac{T_{i}\left(w_{i} \tau_{i n}\right)^{-\theta}}{\sum_{k=1}^{N} T_{k}\left(w_{k} \tau_{k n}\right)^{-\theta}}$, which also represents the fraction of the intermediate goods that country $n$ buys from country $i$. Hence, country $n$ 's total spending on the intermediate-goods from country $i$ is as

$$
\tilde{X}_{i n}=\tilde{\pi}_{i n} \tilde{X}_{n}=\frac{T_{i}\left(w_{i} \tau_{i n}\right)^{-\theta}}{\tilde{\Phi}_{n}} \tilde{X}_{n},
$$

where $\tilde{\Phi}_{n}=\sum_{k=1}^{N} T_{k}\left(w_{k} \tau_{k n}\right)^{-\theta}$ is country $n$ 's price parameter of intermediate-goods. In (7), the total output of the intermediate goods in country $i$ is given as $\tilde{Y}_{i} \equiv \sum_{n=1}^{N} \tilde{X}_{i n}=\left(T_{i} w_{i}^{-\theta}\right) \Omega_{i}^{-\theta}$, where $\Omega_{i}^{-\theta}=\sum_{n=1}^{N} \frac{\tau_{i n}^{-\theta}}{\tilde{\Phi}_{n}} \tilde{X}_{n}$. Then, we get $T_{i} w_{i}^{-\theta}=\tilde{Y}_{i} \Omega_{i}^{\theta}$. Upon plugging the above expression into (7), with $\tilde{P}_{n}=e^{-\eta_{e} / \theta} \tilde{\Phi}_{n}^{-1 / \theta}$, we obtain the gravity equation of the intermediate goods:

$$
\tilde{X}_{i n}=e^{\eta_{e}} \frac{\tau_{i n}{ }^{-\theta}}{\left(\tilde{P}_{n} \Omega_{i}\right)^{-\theta}} \tilde{X}_{n} \tilde{Y}_{i} .
$$

\subsection{The Final Goods Sector}

The budget constraint for country n's total spending on the final goods is as

5 In Eaton and Kortum's [7] model, an idea in a country $i$ is drawn from a Pareto distribution $H_{i}(z)=1-z^{-\theta}$, and a firm in the country employs the idea to produce a specific intermediate good. The chance if the idea is the best idea that leads to the lowest cost in production and commands a mark-up of at least $m>1$ in country $n$ is $b_{i n}(m)=\int_{1}^{\infty} 1-G_{n}\left(m w_{i} \tau_{i n} / z\right) d H_{i}(z) \cong \tilde{\pi}_{i n} / T_{i} m^{\theta}$. The probability of a mark-up of at least $m$ given that the idea is a successful idea in country $n$ is then $b_{i n}(m) / b_{i n}(1)=m^{-\theta}$, which implies that the markup that is conditional on the idea being the best idea follows a Pareto distribution with a parameter $\theta$ as $H(\theta)=1-m^{-\theta}$. The net profit share from producing the intermediate good is $1-m^{-1}$, so that the expected share of the profits from the best idea in a market is as $\int_{1}^{\infty}\left(1-m^{-1}\right) d H(m)=(1+\theta)^{-1}$. 


$$
X_{n}=\sum_{i=1}^{N} X_{i n}
$$

where $X_{\text {in }}=p_{\text {in }} y_{\text {in }}=\pi_{\text {in }} X_{n}$ and $p_{\text {in }}$ denotes price of the final good $i$ in country $n$. Solve (1) with the constraint in (9) to get the imports of good $i$ by country $n$ :

$$
X_{\text {in }}=\left(p_{\text {in }} / P_{n}\right)^{1-\sigma} X_{n},
$$

where $P_{n}=\Phi_{n}^{1 /(1-\sigma)}$ is the price index of final goods and $\Phi_{n} \equiv\left[\sum_{k=1}^{N}\left(p_{k k} \tau_{k n}\right)^{1-\sigma}\right], \forall n$. In (9) and (10), we obtain $\pi_{\text {in }}=\left(p_{\text {in }} / P_{n}\right)^{1-\sigma}$ to represent the contribution of country $i$ 's final-good on country n's spending.

Demand equals supply in the final good sector in equilibrium. With (10), we get

$$
Y_{i}=\sum_{n=1}^{N} X_{i n}=p_{i i}{ }^{1-\sigma} \Pi_{i}^{1-\sigma}
$$

where $\Pi_{i}^{1-\sigma}=\sum_{n=1}^{N} \tau_{i n}^{1-\sigma} P_{n}^{\sigma-1} X_{n}$. We can rewrite (11) to get $p_{i i}{ }^{1-\sigma}=Y_{i} \Pi_{i}^{\sigma-1}$. Plugging the above relation into (10), we obtain the exports of the final-good from country $i$ to country $n$ :

$$
X_{i n}=\frac{\tau_{i n}{ }^{1-\sigma}}{P_{n}{ }^{1-\sigma} \Pi_{i}^{1-\sigma}} Y_{i} X_{n}
$$

\subsection{Equilibrium}

In equilibrium, the total sales of the intermediate goods are equal to their total output, with equation (7), so we have $\tilde{Y}_{i}=\sum_{n=1}^{N} \frac{T_{i}\left(w_{i} \tau_{i n}\right)^{-\theta}}{\tilde{\Phi}_{n}} \tilde{X}_{n}$. Note that, in general equilibrium, Eaton and Kortum [7] show that $r_{i}=r$, $\forall i$, when population growth rates are the same across countries. Since labor supply is inelastic supply in each country in this model, we take this result as given. Then, if being under free trade, with equation (5), we return to the Eaton and Kortum's [7] model:

$$
\left(\frac{w_{i}}{w_{j}}\right)=\left(\frac{T_{i} / L_{i}}{T_{j} / L_{j}}\right)^{\frac{1}{1+\theta}}, \forall i, j .
$$

\section{Trade Elasticity}

As is well known, in addition to final-good trade, the strategy of international outsourcing is popularly employed by the world's most productive firms, such as Apple, Microsoft, Sony, Nokia, Hewlett-Packard, and many others. ${ }^{6}$ These firms contract with specialized

\footnotetext{
${ }^{6}$ For example, Apple designed most of the system architectures for the iPod, iPad and iPhone in-house, but simultaneously outsourced more than 99 percent of these consumer electronics' intermediate inputs to the low-wage Asia-Pacific region [19].
}

Original Equipment Manufacturing (OEM) or Electronics Manufacturing Service (EMS) providers that offer customized manufacturing services, such as Foxconn. International outsourcing also prevails in labor-intensive products, such as athletic and casual footwear. ${ }^{7}$ To cope with real practices, therefore, we instead consider that a country's total exports consist of exports of both final and intermediate goods in the following.

Alvarez and Lucas [10] presume that final goods are not tradable in their model. Instead, we allow the final goods to be tradable, inasmuch as the intermediate goods are also tradable. In this current model, the final goods are the Armington-type goods. The Armington type of final goods generates no extensive margin, such that the net impact of consumers' preferences on trade elasticity should not be completely cancelled out.

With (8) and (12), the total exports from country $i$ to $n$ is then given by

$$
E_{i n}=X_{i n}+\tilde{X}_{i n}
$$

Define $\mu_{\text {in }} \equiv \tilde{X}_{\text {in }} / X_{\text {in }}$ to denote the ratio of intermediate to final goods that are exported from country $i$ to country $n$, and which can be rewritten as

$$
\mu_{i n}=\alpha \tilde{\pi}_{i n} / s_{i}, 8
$$

where $s_{i} \equiv X_{i} / \sum_{n=1}^{N} X_{n}=X_{i i} / Y_{i}$ represents the share of country $i$ in world income and also represents country $i$ 's share of its own output. ${ }^{9}$

Hummels, Ishii, and $\mathrm{Yi}$ [14] define the vertical specialization/international outsourcing of a country as the share of the country's usage of imported inputs in producing final-goods. Per their definition, we define the share of international outsourcing for a country $i$ as a whole as $z_{i} \equiv \sum_{n \neq i}^{N} \tilde{X}_{n i} / Y_{i}$, where $\sum_{n \neq i}^{N} \tilde{X}_{n i}$ is the total imports of intermediate inputs in country $i$ from the other countries abroad. We further define $z_{i n} \equiv \tilde{X}_{n i} / Y_{i}$ to represents the share of international outsourcing of

7 For example, the Taiwanese Pou Chen Corporation produces more than 200 million pairs of shoes annually for Nike, Adidas, and New Balance under OEM/ODM contracts [20].

8 With (14), we can rewrite $\mu_{i n}=\frac{\tilde{X}_{i n}}{X_{i n}}=\frac{\tilde{\pi}_{i n} \tilde{X}_{n}}{s_{n} Y_{i}}=\alpha \frac{\tilde{\pi}_{i n}}{s_{i}} \frac{s_{i} Y_{n}}{s_{n} Y_{i}}$ as

$s_{i}=X_{i i} / Y_{i}$. With (6), we get

$\frac{s_{i}}{s_{n}} \frac{Y_{n}}{Y_{i}}=\frac{X_{i}}{X_{n}} \frac{Y_{n}}{Y_{i}}=\frac{1-(1+\theta) r_{n}}{1-(1+\theta) r_{i}}=1$

while $r_{i}=r_{n}, \forall i, n$ (e.g., Eaton and Kortum, 2001), such that $\mu_{i n}=\alpha \tilde{\pi}_{i n} / s_{i}$. Alternatively, in real practice, we have $1>>r_{i}>0, \forall i$, so that $\mu_{i n} \cong \alpha \tilde{\pi}_{i n} / s_{i}$.

${ }^{9}$ Note that in (10), $\pi_{i n}=X_{i n} / X_{n}$ denotes the share of country $i$ 's income spending on country n's final-good. Therefore, the share of country $i$ 's income spending on its own final-good is given by $\pi_{i i}=X_{i i} / X_{i}$. On the other hand, $s_{i}$ also represents country $i$ 's share of its output, so that $\pi_{i i}=s_{i}$. 
country $i$ that is contributed by country $n$. Then, in aggregate, we have $z_{i} \equiv \sum_{n \neq i}^{N} \tilde{X}_{n i} / Y_{i}=\sum_{n \neq i}^{N} z_{n i}$.

As implied in (2), the total demand for the intermediate goods of country $n$ is as $\tilde{X}_{i}=\alpha Y_{i}$. Recall in (7), that we have $\tilde{X}_{i n}=\tilde{\pi}_{i n} \tilde{X}_{n}$. Putting them together, the share of international outsourcing of country $i$ that is contributed by country $n$ is

$$
z_{\text {in }}=\alpha \tilde{\pi}_{n i}
$$

For a country as a whole, as defined above, the share of international outsourcing the country $i$ engages in is $z_{i} \equiv \sum_{n \neq 1}^{N} z_{n i}$. From (16), we obtain

$$
z_{i}=\alpha\left(1-\tilde{\pi}_{i i}\right)
$$

where $\quad \tilde{\pi}_{i i}=T_{i}\left(w_{i}\right)^{-\theta} / \sum_{k=1}^{N} T_{k}\left(w_{k} \tau_{k n}\right)^{-\theta} \quad$ is the probability that country $i$ is the lowesr cost suppliers for any intermediate-goods in the domestic market and which captures the comparative advantages of country $i$.

Combining (15) and (16), we obtain $\mu_{\text {in }}=z_{\text {in }} / s_{i}$. Taking the differentiating logarithm of (14) with respect to trade cost in absolute value, we obtain the trade elasticity as $\varepsilon_{i n} \equiv\left|\frac{d \ln E_{i n}}{d \ln \tau_{\text {in }}}\right|=\frac{1}{1+\mu_{i n}}(\sigma-1)+\frac{\mu_{\text {in }}}{1+\mu_{\text {in }}} \theta$, and this can be expressed as

$$
\varepsilon_{\text {in }}=\left(\frac{s_{i}}{s_{i}+z_{\text {in }}}\right)(\sigma-1)+\left(\frac{z_{\text {in }}}{s_{i}+z_{\text {in }}}\right) \theta .
$$

When there is no intermediate-goods production as $z_{\text {in }}=0$, equation (18) returns to the Armington model, and the associate trade elasticity becomes $\varepsilon_{i n}=\sigma-1$, $\forall i, n$. If a country is substantially small such as $s_{i} \rightarrow 0$ and all tradable goods are intermediate-goods, we then obtain $\varepsilon_{i n} \rightarrow \theta, \forall i, n$. This is in line with Costinot and Rodriguez-Clare [17], who introduce tradable intermediate-goods into the Eaton and Kortum [8] model and show that trade elasticity remains constant as $\varepsilon=\theta$. In the model of Costinot and Rodriguez-Clare [17], the extent to which international outsourcing is conducted is both exogenous and symmetric for all countries. To the contrary, in this current model, as implied in (16), the international outsourcing is endogenous and asymmetric. After all, in real practice, international outsourcing activities that are carried out differ substantially across countries.

As argued above, we presume that there are no selection effects on final-goods producers, but there are selection effects on intermediate-goods producers. Therefore, when world trade is mixed with final goods and intermediate goods, equation (18) shows that trade elasticity is a linear combination of consumers' preference (governed by elasticity of substitution parameter $\sigma-1$ ) and producers' comparative advantages (governed by the dispersion-of-productivity parameter $\theta$ ), ranging along $[\sigma-1, \theta]$. This is the first implication of this model.
Given $\theta>\sigma-1,{ }^{10}$ it also implies in (18) that scale matters for a country's trade elasticity, and that small countries tend to have a larger trade elasticity. As a result, there exists heterogeneity in the growth rates of sales among countries after trade liberalization. Arkolakis [18] argues that trade liberalization benefits relatively more the smaller exporting firms in a market. In comparison to Arkolakis [18], this current model implies that trade liberalization benefits smaller countries, ceteris paribus, relatively more (exports) than larger ones. This is the second implication in this model. We summarize the above two implications on aggregate trade elasticity as below:

Proposition 1. A country's trade elasticity is determined not only by consumers' preferences but also producers' comparative advantages, and smaller countries tend to have larger trade elasticity.

\section{Gains from Trade}

Recall in (10) that $\pi_{i n}=\left(\frac{p_{\text {in }}}{P_{n}}\right)^{1-\sigma}$ and in (2) that $p_{i}=\frac{\sigma \tilde{A}_{i}^{-1}\left(w_{i}^{1-\alpha} \tilde{P}_{i}^{\alpha}\right)}{\sigma-1}$, thus we get

$$
\pi_{i i}=\left(\frac{\sigma \tilde{A}_{i}^{-1}}{\sigma-1}\right)^{1-\sigma}\left(\frac{w_{i}^{1-\alpha} \tilde{P}_{i}^{\alpha}}{P_{i}}\right)^{1-\sigma} .
$$

We also have $\tilde{\pi}_{i n}=\frac{T_{i}\left(w_{i} \tau_{i n}\right)^{-\theta}}{\tilde{\Phi}_{n}}$ and $\tilde{P}_{n}=e^{-\eta_{e} / \theta} \tilde{\Phi}_{n}^{-1 / \theta}$ in (7), which leads to $\tilde{P}_{i}=e^{\eta_{e} / \theta} T_{i}^{-1 / \theta} \tilde{\pi}_{i i}^{1 / \theta} w_{i}$. Putting them together, we thus obtain

$$
\pi_{i i}=\gamma_{i} T_{i}^{-\alpha(1-\sigma) / \theta} \tilde{\pi}_{i i}^{\alpha(1-\sigma) / \theta}\left(w_{i} / P_{i}\right)^{1-\sigma},
$$

where $\gamma_{i}=\left(\frac{\sigma \tilde{A}_{i}^{-1}}{\sigma-1}\right)^{1-\sigma} e^{\eta_{e} \alpha(1-\sigma) / \theta}$. It is easy then to obtain the real wage from above as:

$$
\frac{w_{i}}{P_{i}}=\gamma_{i}{ }^{\frac{-1}{1-\sigma}} T_{i}^{\frac{\alpha}{\theta}} \pi_{i i}^{\frac{-1}{\sigma-1}} \tilde{\pi}_{i i}^{\frac{-\alpha}{\theta}} .
$$

The change in welfare after open trade in country $i$ is defined as the change in real wages, which is the so called gains from trade. Arkolakis et al. [1] define the gains from trade as $G T_{i} \equiv W_{i} / W_{i}^{a}$, where a denotes autarky and $W_{i} \equiv w_{i} / P_{i}$ is the real wage. Per their definition, the change in welfare (free trade vs. autarky) in this model is as

$$
G T_{i}=\pi_{i i}{ }^{\frac{-1}{\sigma-1}} \tilde{\pi}_{i i}{ }^{-\alpha \frac{1}{\theta}},
$$

which is determined by both consumer preference $(\sigma-1)$ and by firms' comparative advantages $(\theta)$ as well. ${ }^{11}$

\footnotetext{
${ }^{10}$ For example, see Eaton and Kortum, [8] and Arkolakis [1].

${ }^{11}$ In autarky, $\pi_{i i}^{a}=\tilde{\pi}_{i i}^{a}=1$.
} 
Recall that $s_{i}=X_{i i} / Y_{i}$ in (15), and that $z_{i}=\alpha\left(1-\tilde{\pi}_{i i}\right)$ in (18). The gains from trade in (20) can now be further rewritten as

$$
G T_{i}=s_{i}^{-\frac{1}{\sigma-1}}\left(1-z_{i} / \alpha\right)^{-\alpha \frac{1}{\theta}},
$$

which shows that the gains from trade increase with a country's size $\left(s_{i}\right)$ as well its share of international outsourcing activities $\left(z_{i}\right)$. We argue that a country's trade volume will be more sensitive to trade costs if the country is engaged in more international outsourcing activities, since intermediate goods are usually higher exposed to transportation frictions while they are shipped back and forth across national borders more than once. ${ }^{12}$ This argument is somehow in line with Costinot and Rodiguez-Clare [17] and Feenstra and Hanson [11] in that welfare improves with international outsourcing.

Equation (21) also implies that scale matters in gains from trade, and that smaller countries tend to benefit with relatively greater gains after trade liberalization. The intuition is simple. Having the Armington-type of final-goods, that trade is purely driven by the love-ofvariety, the smaller country trades with the world with a larger share of its output, hence having more gains from trade. This implication corresponds to Proposition 1, which implies that trade liberalization benefits smaller countries, ceteris paribus, relatively more (exports) than larger ones. We use Proposition 2 to summarize the above two implications.

Proposition 2. A smaller country that is engaged in more international outsourcing activities tends to benefit with relatively greater gains from trade after trade liberalization.

\section{Concluding Remarks}

We have presented a simple model to show that trade elasticity is determined by not only consumers' preference but also producers' comparative advantages, and that smaller countries tend to have larger trade elasticity compared to larger countries. In a world where trade is driven by not only consumers' love-of-variety, but also producers' comparative advantages, trade elasticity might be understated if we consider trade pattern as being purely driven by consumers' love-of-variety preferences on the demand side, while conversely it might be overstated if we consider trade pattern as being entirely driven by producers' comparative advantages on the supply side.

In addition to international outsourcing, this paper shows that scale matters in both trade elasticity and gains from trade. There is also heterogeneity in the growth rates of exports among countries after trade liberalization. Particularly, smaller countries that are engaged in more international outsourcing activities tend to acquire greater gains from trade after trade liberalization.

\footnotetext{
${ }^{12}$ Nevertheless, in contrast to Feenstra and Hanson's [11] model, wherein the gains from trade for unskilled workers are conditional on when international outsourcing $z_{i}$ is sufficiently small, equation (21) implies that international outsourcing is explicitly welfare improving while we presume one type of workers.
}

\section{Support}

The financial support provided by Taiwan's Ministry of Science and Technology (104-2410-H-002-009-MY2) is gratefully acknowledged.

\section{References}

[1] Arkolakis, Costas, Costinot Arnaud, and Andres Rodiguez-Clare, 2012. 'New Theories, Same Old Gains?' American Economic Review, 102 (1):94-130.

[2] Armington, Paul, 1969, 'A Theory of Demand for Products Distinguished by Place of Production', International Monetary Fund Staff Papers, XVI (1969), 159-78.

[3] Krugman, Paul R, 1980. 'Scale Economies, Product Differentiation, and the Pattern of Trade,' American Economic Review, 70(5): 950959

[4] Anderson, James E. and Yoto V. Yotov, 2010. 'The Changing Incidence of Geography,' American Economic Review, 100(5): 2157-86.

[5] Axtell, Robert L. 2001. 'Zipf Distribution of U.S. Firm Sizes,' Science, 293: 1818-1820.

[6] Luttmer, Erzo G. J., 2007. 'Selection, Growth, and the Size Distribution of Firms,' The Quarterly Journal of Economics, 122 (3): 1103-1144.

[7] Eaton, Jonathan and Samuel S. Kortum, 2001. 'Technology, Trade, and Growth: A Unified Framework,' European Economic Review, 45: 742-755.

[8] Eaton, Jonathan and Samuel S. Kortum, 2002. 'Technology, Geography, and Trade,' Econometric, 70 (5), 1741-1779.

[9] Chaney, T, 2008. 'Distorted Gravity: Heterogeneous Firms, Market Structure, and the Geography of International Trade,' American Economic Review, 98: 1707-1721.

[10] Alvarez, Fernando and Robert Lucas, Jr., 2007. 'General Equilibrium Analysis of the Eaton-Kortum Model of International Trade,' Journal of Monetary Economics, 54(6): 1726-1768.

[11] Feenstra, R. C., Hanson, G. H., 1996. 'Foreign investment, outsourcing and relative wages', The Political Economics of Trade Policy: Papers in Honor of Jagdish Bhagwati, MIT Press, 89-127.

[12] Antràs, P. and E. Helpman, Global Sourcing, 2004. J. Political Economy 112, 552-80.

[13] Grossman, Gene and Helpman, Elhanan, 2002. 'Integration vs. Outsourcing in Industry Equilibrium', Quarterly Journal of Economics, 117, 85-120.

[14] Hummels, David, Jun Ishii and Kei-Mu Yi , 2001. 'The nature and growth of vertical specialization in world trade,' Journal of International Economics, 54 (1): 75-96.

[15] Koopman, Robert, Zhi Wang, and Shang-Jin Wei. 2014. 'Tracing Value-Added and Double Counting in Gross Exports', American Economic Review, 104(2): 459-94.

[16] Caliendo, Lorenzo and Parro, Fernando, 2015. 'Estimates of the Trade and Welfare Effects of NAFTA,' Review of Economic Studies, 82(1): 1-44

[17] Costinot Arnaud, and Andres Rodiguez-Clare, 2013. 'Trade Theory with Numbers: Quantifying the Consequences of Globalization', Handbook of International Economics, Volume 4, edited by G. Gopinath, E. Helpman, and K. Rogoff.

[18] Arkolakis, Costas, 2010. 'Market Penetration Costs and the New Consumers Margin in International Trade,' Journal of Political Economy, 118(6): 1151-99.

[19] Einhorn, B., 2007. 'Apple's Chinese Supply Lines,' January 8, 2007, BusinessWeek.

[20] Lo, Chu-Ping, Su-Ying Hsu, and Shih-Jye Wu, 2014. 'The role of overseas Chinese-speaking regions in global sourcing,' China Economic Review, 30: 133-142. 